\title{
A Taxonomy of Event Participants Based on Risk and Security Perceptions
}

\author{
Hannah Carter \\ Miguel Moital \\ Department of Events \& Leisure \\ Faculty of Management \\ Bournemouth University \\ United Kingdom
}

\begin{abstract}
Purpose: This paper puts forward a taxonomy of event participants based on risk and security perceptions.

Design/methodology/approach: Two focus groups were established with British mothers, one with five mothers and the other with six, recruited through convenience and snowball sampling. A tree diagram was employed to uncover the taxonomic structure underlying risk and security perceptions. In creating the taxonomy, two critical issues were found to best categorise participants: the extent to which risks were considered before attending an event and whether or not participants showed an interest in knowing about security measures in advance of the event.

Findings: Six taxonomy categories were created, based on the unique combination of attitude and reactions: Overthinker, Investigator, Naïve, Ignorer, Survivalist and Optimiser. Similarities and differences between the types of participants were examined across twelve typical traits and reactions to risk and security.

Originality/value: Existing taxonomies have tended to identify customer types based on risk perceptions alone. This research expands such work by considering attitudes towards both risk and security and how these affect event attendance. Hence, the descriptive taxonomy developed in the paper provides empirical evidence of the diverse risk and security perceptions at public events.
\end{abstract}

Keywords: Risk perceptions, Taxonomy, Event attendance, Security perceptions

Cite as

Carter, H. and Moital, M., 2018. A Taxonomy of Event Participants Based on Risk and Security Perceptions, Journal of Hospitality \& Tourism Insights, forthcoming 


\section{A Taxonomy of Event Participants Based on Risk and Security Perceptions}

\section{Introduction}

Planned events pervade modern life and according to Getz and Page (2016) their celebratory and festive ambience is often what attracts people to them. However, like any other service, there are risks associated with consuming them, with media often reporting on incidents affecting participants which have ruined the positive ambience for which events are known. These include infrastructure malfunction (Globo, 2017), fires (Guardian, 2017), violence and sexual harassment (Chicago Tribune, 2018), theft (The Outline, 2018) and food poisoning (The Daily Meal, 2017). Recently, due to growing security threats, these events have become easy targets for terrorism and a number of recent high-profile incidents have received extensive media coverage, both in traditional and social media, with incidents taking place in open public spaces such as the Boston Marathon bombings (New York Times, 2013), as well as restricted access spaces such as the Ariana Grande concert in Manchester (BBC, 2017). Such incidents can potentially change the extent to which people perceive attending events to be associated with risks, be it a functional, physical, financial, social or psychological loss (Bruwer and Rawbone-Viljoen, 2013).

Bearing in mind that "events and festivals are particularly prone to hazardous factors that create a possibility of harm to (...) the crowd" (Wynn-Moylan, 2017), event managers feel the need to reassure event participants that they have nothing to worry about, and that the event will be safe. While it may be difficult or impossible to deal with some of the risks in advance (Kaplan and Mikes, 2012), there are risk reduction strategies which can be put in place (Slovic, 2000) in the form of security measures (e.g. video surveillance, greater police presence, cement blocks, vehicle monitoring). In fact, past research has suggested that as more security incidents happen, the introduction of security measures escalates (Toohey and Taylor, 2008). Security measures have been found to reassure consumers (Bruwer and Rawbone-Viljoen, 2013); however, some of these measures can have a detrimental effect on the event experience (Jayawardhana, 2016), and the publication of security measures may create fear in some (Kovacich and Halibozek, 2006) and enhance the likelihood of security breaches (Bennett and Haggerty, 2012).

In this evolving security environment, understanding how people react to risk and security in the context of event attendance becomes of paramount importance. Ultimately, consumers are likely to consider risk and safety more during the event decision-making process, with potential consequences for event attendance if these are not effectively managed. As a first step, work needs to be carried out in order to identify different types of attitudes towards risk and security and how these affect event attendance. Evidence of different reactions to risk and security perceptions exists in other fields such as tourism (e.g. Roehl and Fesenmaier, 1992; Floyd and Pennington-Gray, 2004; Dolnicar, 2005) and food (Mitchell and Boustani, 2015), but research in events is very limited and restricted to risk perceptions (e.g. Saadat et al, 2010; Schroeder et al, 2013; Walters et al, 2017). The purpose of this research was therefore to create a taxonomy of event participants based on risk and security perceptions. A taxonomy is a development of segments or personality traits, which are built upon through research to create an ever-clearer picture of each segment's individual characteristics (Jackson and Groves, 2015). 


\section{Literature review}

Consumer decisions involve risks when the outcomes of a decision remain uncertain (Roehl and Fesenmaier, 1992). Perceptions of risk result from an interaction between the probability of a loss being incurred and the expected magnitude of the loss (Mitchell, 1999). Consumers interpret the probability and impact of these risks in different ways, and therefore hold what is commonly called risk perceptions. From a consumer decision-making perspective, research on risk perceptions encompasses two broad areas: those related to how risk perception affects decision-making (process theories) and the types of perceived risks that could affect consumer decision-making (content theories). Common types of risk include financial, performance, psychological, physical, social and time (Bruwer and Rawbone-Viljoen, 2013). This research is underpinned by the way in which event participants view risks rather than what risks they envisage and therefore this research draws mainly on process theories, reviewed in the next section. In order to persuade consumers that the probability of incidents happening is low, and should incidents happen the impact will be limited and mitigated, marketers put in place security measures. Therefore, security perceptions are also reviewed.

\subsection{Risk perception}

Several theories have been put forward to understand risk perception and how it influences decision-making. Maximisation Theory, one of the earliest theories, explains decisionmaking by assuming that the individual will maximise the expected utility (Slovic, 2000). In the context of risk perceptions this means that consumers will make a rational decision which allows them to be the most satisfied, in spite of any risks. To overcome the criticism that there is more to the decision-making than just picking the one with the most satisfaction (DeLamater, and Ward, 2013), Rational Choice Theory was developed. This approach assumes decision-making results from logical and well thought out choices, with the consumer selecting the alternative that provides the greatest level of satisfaction, bearing in mind both costs and benefits (Jaeger et al., 2001). This means individuals will consider the benefits and the risks they think may occur when making a decision to attend an event.

Cultural Theory departs from the assumption that humans are rational beings by proposing the idea that individuals select what they fear to correspond with their cultural biases - their values and beliefs (Douglas, 1978). For example, incidents caused by guns are likely to be more salient in the US then in the UK given the cultural background of both countries. The Psychometric Paradigm has been explained in cognitive psychology, which conceptualises risks as 'subjective expressions of individual fears or expectations about unwanted consequences of actions or events' (Jaeger et al., 2001, p. 102). It has been found that many people attempt to balance out their risk-taking by strategically choosing an option that ensures a satisfactory level of benefit but more importantly avoids major disaster (Jungermann et al., 1998). Personality Theory, in turn, assumes that some people enjoy taking risks, and therefore will do this on a consistent basis, whereas others are naturally more risk-averse (Wildavsky and Dake, 1990). This can explain the different decisions made by individuals once they perceive risks, leading to the concept known as risk propensity, defined as how likely it is that individuals will take a risk (Stewart et al., 2001).

Knowledge Theory is based on the idea that individuals fear something because they know they should. A good example of this is terrorism; people fear it because they have learned that it can be catastrophic (Krimsky and Golding, 1992). Knowledge theory appears to be becoming more relevant, as traditional and social media portray information which injects fear into individuals. While people have always had knowledge of what could occur, the media storm after major events makes it worse, as people have more information almost 
immediately (Fischer et al., 2011). Finally, unlike all the previous theories which assume that cognitive processes are the main driver of risk perception and decision-making (Lavino and Neumann, 2010), James' (1913) Emotion Theory emphasises the role of emotions, because over time certain emotions can become associated with a particular experience, therefore meaning that even before that experience begins, emotions are anticipated by the body and thus triggered, removing the amount of control individuals have over their emotions.

\subsection{Risk reduction and security measures}

When significant risks are identified, consumers look for ways to reduce the probability of incidents happening and, should incidents happen, to limit or mitigate their impact. Sometimes consumers adopt risk reductions strategies themselves independently of the marketer (Fuchs and Reichel, 2011), while in other situations they are able to evaluate security measures put in place by the marketer. The latter case has received some attention, with a number of studies focusing on security measures and consumer behaviour, both within and outside the events literature. Security measures are put in place to protect consumers against loss, injury, death or damage to belongings and property and can take the form of physical devices or staff behaviour (Rittichainuwat and Chakraborty, 2012). Measures can be overt, in which case they are seen by tourists to reassure them, or covert if they are present without consumers noticing (Rittichainuwat, 2013).

Not surprisingly, research has found that security measures can increase perceived safety (Nissen and Heir, 2016; Milman Jones and Bach, 1999). In tourism, studies have examined security measures at the destination level (Rittichainuwat and Chakraborty, 2012), while others focused on specific services such as hotels (Chan, and Lam, 2013). However, personal characteristics can affect the extent to which security measures affect perceptions of safety. Milman Jones and Bach (1999) found that crime victimization by the respondent or an immediate family member had an effect on how safety devices affected vacation tourists' perception of safety, while Rittichainuwat and Chakraborty (2012) concluded that leisure and business tourists attached different importance to security measures. Research on how security measures influence event attendance is virtually non-existent. One notable exception is the study by Taylor and Toohey (2006), which examined how obvious security measures were at the Rugby World Cup. They found that perceptions of security measures within the event site were higher among international attendees.

\subsection{Taxonomies based on risk and security perceptions}

A number of taxonomies based on risk perceptions have been developed, including those based on types of risks which people associate with consuming the product (e.g. Roehl and Fesenmaier, 1992; Seabra et al, 2013), risk propensity (Hajibaba et al, 2015) or what incidents are perceived as risky (Dolnicar, 2005), and therefore they were approached from a content rather than process perspective. Schroeder et al (2013), in contrast, adopted aprocess perspective when developing three traveller risk types (risk averse, neutral and tolerant) based on overall the amount of risk tourists' associate with travel in general. Others went further and segmented travellers based on perceived risk and security. Floyd and Pennington-Gray (2004) and Ritchie et al (2017) added the security component to the segmentation exercise, with the former including one item related to the adoption of security measures by providers (airports) and the latter restricting their analysis to measures the consumer takes (as opposed to what the provider does). Overall, these studies highlight the appropriateness and usefulness of using risk and security perceptions as a basis for creating taxonomies of consumers; however they mainly consider risk perceptions with 
security perceptions taking on a minor role. Furthermore, all these studies illustrate that there are a number of levels at which individuals can perceive risk, with some naturally worrying more than others. These reasons, coupled with the fact that by segmenting individuals by risk and safety attitudes it is possible to better understand buying behaviour, suggest that examining patterns of reaction based on risk and security perceptions is worthy of study.

\section{Research Methodology}

The literature review on risk and security perceptions provided strong evidence that consumers react to them differently. Therefore, event managers have not only to be aware of the nature of these differences, but also to design the marketing of the event to respond to these differences, by dealing with risk and safety management both before and during an event. As a result, creating a taxonomy will allow managers to effectively segment behaviours and assure the needs of different groups are being met by the marketing of the event. Yet, as shown in the previous section, few studies incorporated both risk and security perceptions, and existing taxonomies tend to consider risk overwhelmingly more than security perceptions. This provides the details of the empirical work carried out in the development of the taxonomy. The focus was on the development of a descriptive taxonomy (Elman, 2005) and therefore on defining categories and what constitutes them.

Focus groups were undertaken as they are inherently a flexible data collection tool (Fox et al, 2014). However, a brief was designed to help centre the discussion around risk and security perceptions and how these affect decision-making and attendance of public events. The points for discussion included the extent to which they worry about risks, how they incorporate risk and security in their information search and decision-making, how they react to strategies put in place by event organisers to deal with any eventuality, past experience of event attendance and how this affects current attitudes towards risk and security, and how recent incidents are affecting their perceptions. Probing was extensively used to elaborate on participants' answers and to adopt a more natural flow (Fox et al, 2014). When the discussion appeared to go off topic, the moderator either picked up on points made by participants or introduced new themes based on the focus group brief.

Mothers were chosen for the study as they tend to attend a large number of events. This therefore means they have a wealth of experience to which they can relate when considering the focus of the research. Research has also shown that in the presence of children, mothers take on more responsibility than fathers for event-related decisions such as travel plan and on-site decisions (Kim et al, 2010). This may be because they are more liable to worry (Freeston et al., 1994), particularly about risks which might occur (Sjoberg, 1998), as protecting themselves and their children from harm is a priority. All participants had attended both public events within recent years, and throughout the study they were asked to consider these events when answering the questions asked. Two focus groups were undertaken in Britain, one with five mothers and the other with six. The research is exploratory (Jones et al., 2012) and focused on a relatively specific group (mothers) in relation to their purchase of one type of product (public events), and therefore small samples are acceptable (Holloway and Wheller, 2010). From the 11 mothers, three had one child, five mothers two children and two mothers had three children. Participants were recruited through convenience and snowball sampling (Fox et al, 2014). A small number of mothers known to one of the researchers were invited to participate and to suggest other mothers. Table 1 provides additional information about the personal context of the participant and events they attended. 
Table 1: Characteristics of participants

\begin{tabular}{|c|c|c|c|c|}
\hline $\begin{array}{c}\text { Name } \\
\text { (Taxonomy type) }\end{array}$ & $\begin{array}{l}\text { Focus } \\
\text { Group }\end{array}$ & $\begin{array}{l}\text { Number of } \\
\text { Children }\end{array}$ & Employment status & Events attended \\
\hline $\begin{array}{c}\text { Clare } \\
\text { (Naïve) }\end{array}$ & FG1 & 1 & Works from home & $\begin{array}{l}\text { Takes her daughter to } \\
\text { smaller, local, music events. }\end{array}$ \\
\hline $\begin{array}{l}\text { Marianne } \\
\text { (Ignorer) }\end{array}$ & FG1 & 2 & Stay at home mother & $\begin{array}{l}\text { Attends mainly local events, } \\
\text { such as country fayres which } \\
\text { she attends with her family } \\
\text { and their dog. }\end{array}$ \\
\hline $\begin{array}{c}\text { Becky } \\
\text { (Overthinker) }\end{array}$ & FG1 & 3 & Works part time. & $\begin{array}{l}\text { Attends small local events but } \\
\text { in the odd occasion also } \\
\text { travels farther to attend them } \\
\text { (e.g. car racing events). }\end{array}$ \\
\hline $\begin{array}{c}\text { Chloe } \\
\text { (Optimiser) }\end{array}$ & FG1 & 3 & Works full time & $\begin{array}{l}\text { Attends mainly small local } \\
\text { events but in the odd } \\
\text { occasion also travels farther } \\
\text { to attend them (e.g. fashion \& } \\
\text { beauty shows). }\end{array}$ \\
\hline $\begin{array}{c}\text { Amy } \\
\text { (Survivalist) }\end{array}$ & FG1 & 2 & Stay at home mother & $\begin{array}{l}\text { Attends mainly small local } \\
\text { events but in the odd } \\
\text { occasion also travels farther } \\
\text { to attend them (e.g. music } \\
\text { festivals) }\end{array}$ \\
\hline $\begin{array}{c}\text { Laura } \\
\text { (Survivalist) }\end{array}$ & FG2 & 1 & Stay at home mother & $\begin{array}{l}\text { Goes to craft events, often } \\
\text { held in venues like NEC } \\
\text { Birmingham. }\end{array}$ \\
\hline $\begin{array}{c}\text { Lucy } \\
\text { (Investigator) }\end{array}$ & FG2 & 2 & Works part time & $\begin{array}{l}\text { Attends country fayre's, goes } \\
\text { to the theatre and public } \\
\text { events like fireworks. }\end{array}$ \\
\hline $\begin{array}{l}\text { Charlotte } \\
\text { (Naïve) }\end{array}$ & FG2 & 2 & Works full time & $\begin{array}{l}\text { Has attended local events } \\
\text { with her children. }\end{array}$ \\
\hline $\begin{array}{c}\text { Grace } \\
\text { (Ignorer) }\end{array}$ & FG2 & 2 & Works full time & $\begin{array}{l}\text { Has been to many swimming } \\
\text { galas and sporting } \\
\text { competitions with her } \\
\text { children. }\end{array}$ \\
\hline $\begin{array}{c}\text { Kerry } \\
\text { (Optimiser) }\end{array}$ & FG2 & 2 & Works full time & $\begin{array}{l}\text { Attends small local events } \\
\text { and goes on holiday a large } \\
\text { amount and attends events } \\
\text { whilst out there. }\end{array}$ \\
\hline $\begin{array}{c}\text { Debbie } \\
\text { (Overthinker) }\end{array}$ & FG2 & 1 & Stay at home mother & Attends fundraising events. \\
\hline
\end{tabular}

The transcriptions of the recordings were analysed in order to identify patterns of reactions to risk and safety when attending events, from which a taxonomy structure could be identified and profiled. According to Doty and Glick (1994: 232), taxonomies are "classification systems that categorise phenomena into mutually exclusive and exhaustive sets with a series of discrete decision rules". One of the key elements in taxonomy development is thus the criteria employed to separate subjects into distinct categories. In this study, the focus was on identifying classifiers that could meet three criteria: a) they represented critical views of risk and security perceptions, b) they facilitated the formation of logical taxonomy categories against which a number of descriptive dimensions could be developed and c) they contributed to designing marketing solutions which address the concerns of the various types of participants in relation to risk and security. In creating the taxonomy, two critical issues were found to best address these three conditions: the extent to which risks were considered before attending an event and whether or not participants showed an interest in knowing about security measures in advance of the event. An additional question was employed to categorise those who answered 'no' to the second 
question. Thus, from the two common ways of creating typologies - matrix and branching tree diagram (Collier et al, 2012) - data analysis suggested that the latter was more appropriate to uncover the taxonomic structure underlying risk and security perceptions. The path leading to the definition of each taxonomy category is shown in Figure 1. In attempting to increase the robustness of and detail about the taxonomy categories, and in line with criterion b) above, typical traits and reactions to risk and security were identified as suggested by Schäfer and Klammer (2016). This resulted in describing each taxonomy category across 12 dimensions, described in the next section.

Figure 1 - Critical path underpinning the definition of taxonomy categories

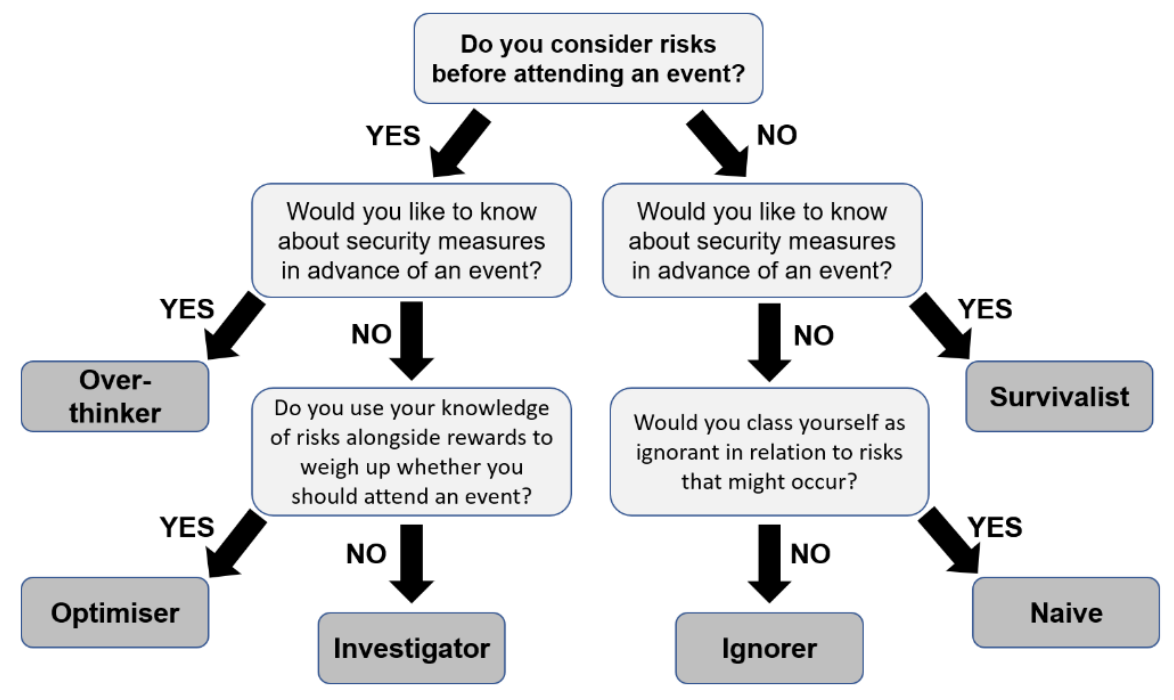

\section{Results}

Figure 2 provides the characteristics of each of the six taxonomy categories. The categories are profiled based on five categories encompassing twelve criteria, thus establishing the similarities and differences between them. The four risk perceptions criteria include overall risk attitude, how knowledgeable about risks they are, the extent to which they consider risks and whether these impact on their decision. Past experience, the second category, is covered by two criteria: how much they consider previous experiences and the type of experience considered (positive or negative). Safety perceptions include overall attitude toward safety, whether or not they want to know about safety measures in advance, how this knowledge impacts them, and the extent to which security measures impact on their decision to attend the event. The final two categories are media sensitivity, which reflects the extent to which media coverage of safety incidents impacts on their attitude towards risk and security, and alternative consideration which focuses on whether they consider alternative events in response to concerns about risk and security. The remainder of this section explains each taxonomy category in detail. 
Figure 2: Characteristics of taxonomy categories

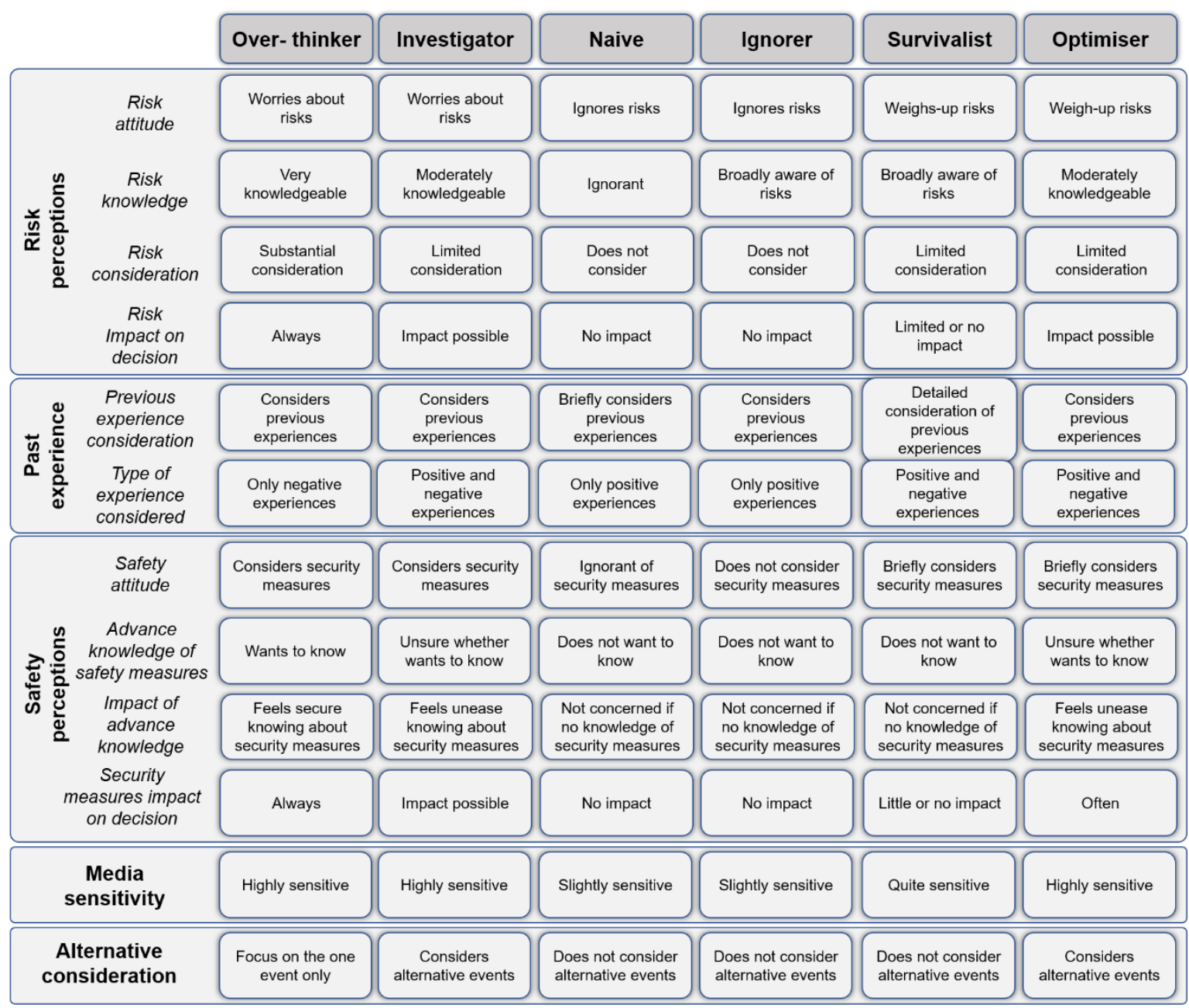

\subsection{Overthinker}

The first of the six types was labelled Overthinker because these are individuals who overthink their decision to attend an event. They worry about risks that might occur, and they make themselves too knowledgeable in this area, which increases their worry and means they over-think risk as a whole:

'If they do take bottles away etc. what if there is someone on the inside who doesn't have to pass security and they bring something in?' (Debbie, FG2).

These individuals are similar to decision-makers. They consider every element, again analysing any decision made and worrying that it could potentially be the wrong one. By giving it too much consideration, they allow risk to always influence their event attendance decision, even if other people would consider this irrational behaviour.

Their attitude towards security measures is very similar, and they think too much about it and like to be aware of what measures are in place in advance of attending an event. This then means that if they cannot find this information or feel the security is not advanced enough, it is likely they would not attend. Overthinkers are also people who can only focus on the one matter in hand; they will not consider alternatives. They can look at basing their decision on previous event experience they have had, but will tend to focus on anything negative that happened whilst they were there, rather than thinking of the positives and the fun they had at the event. Ultimately risk and security does impact their decision. However 
they may still attend an event, but would spend time there worrying about what might happen, and on arrival they would consider exit options, as Becky (FG01) expressed:

'on arrival at a venue I would check for fire exits and the nearest point of entry/exit access in case anything were to occur'.

It suggests that they can demonstrate an almost paranoid behaviour towards perceived risks.

\subsection{Investigator}

The second type, Investigators, are a less extreme version of Overthinkers. They actively consider the risks related to their decision and spend time seeking knowledge to re-assure their decision despite concerns they might have, but to a lesser extent than Overthinkers. They therefore do consider risks, but only moderately and ultimately this can impact their decision, depending on the degree of the risk. With regard to security measures they do consider them, and it can make them reassured knowing about the exact measures in place in advance:

'It can be reassuring, particularly when you're in a tight space with a lot of people'. (Lucy; FG2)

Even though they appreciate the benefits of the presence of security measures, they feel unsure about whether they would like to know about security in advance of the event. This means overall security measures in place could affect their decision, but it is much less likely to than it is to impact Overthinkers. Investigators are fair when considering previous experiences they have been through; they consider both the positive and negative experiences, to weigh up the risks that occurred and might occur again. This will cause them concern, but they feel re-assured knowing that they have considered the past and the likelihood of risk occuring. As Lucy (FG2) said,

'When I attend events, I think about security measures at previous events'.

When asked why she did this, she referred to the fact that risks make her feel uncomfortable, and by thinking about them in advance she can plan for them. Investigators stress the importance of alternative event options, allowing them to consider similar events they could go to and to compare risk and security levels at both events. This then allows them to make an informed decision, with risk perceptions possibly influencing their decision.

\subsection{Naïve}

Naïve, the next type, is based on the idea that those who are ignorant are happy. Their overall attitude towards risk and security is an oblivious one. Their main attribute is that they are so laid back, due to their ignorance, that things such as risk do not cross their mind. Risk does not worry these individuals as they have no knowledge of it.

'I don't really think it's important to me, if I want to go to an event I'll go, something could happen at any event' (Charlotte, FG2).

Their attitude is similar in relation to security measures at events, they do not think about them and therefore have no need to know what measures are in place in advance of an event taking place.

'I don't think I've ever really sat and thought it through until now, it definitely isn't something that crosses my mind' (Clare, FG1) 
As a consequence, security levels will not impact their decision to attend an event. The main element Naïve individuals take into consideration is past experiences, and they focus their memories on all the fun they had. It is likely that if they have attended an event and something bad has happened, they have done their best to forget about this, and do not let it influence their attendance decision in the future. Naïve individuals choose to not worry about alternative options; they are satisfied that they want to attend this event because it is their first choice, therefore that is what they are going to do. Clare (FG01) illustrated this point it well:

'Ultimately if you don't go to things you are constraining your life to things that might not happen'.

\subsection{Ignorer}

Ignorer is the type for those who are risk takers. They are aware of risk, but they consciously choose to ignore it and make event attendance decisions based on other factors. They have little knowledge of the risks and as a result they do not allow risk to impact their decisions.

'If there are people there who are bad you can't tell who they are, there's no point worrying' (Marianne, FG1).

The main decision-making factor for lgnorers is previous experiences, where they remember all the good times they had.

'When I take the kids places I don't think about what bad could happen, we just chat about the fun we've had before' (Grace, FG2).

This therefore justifies disregarding any risk they might know about. It also explains why they do not feel the need to consider alternative events; for these individuals knowing they have or can have a good time at an event is enough to take any risk. With regard to lgnorers and security measures, they are very similar to Naïve individuals, in that they choose to not concern themselves with what security is in place; and they don't want to know about measures in advance of an event. When asked if she wanted to know about security measures in advance. Marianne (FG1) said 'no'.

Overall this demonstrates that Ignorers are risk takers, they may be aware of risks that are there, but consciously ignore them due to the good time they are going to have. These individuals believe life is for the living, and therefore do not worry themselves with what might occur at events.

\subsection{Survivalist}

Survivalists are people who have lived through bad experiences, such as terror attacks, and therefore live their life believing that 'If it's my time, it's my time' (Laura, FG2). People who fall into this category tend to be older and have survived previous bad experiences, so believe that it all comes down to luck. When considering attending an event, and looking at the risks they perceive to be there, Survivalists weigh up the risks, they are fully aware of them, and want to consider them, in spite of the fact that they know it is unlikely to change their opinion unless the situation is extraordinary:

Laura (FG2) 'it depends how they presented it, if they make a big deal of security you might start thinking woo, what's going to happen?'.

This demonstrates their intrigue by security, even if ultimately it won't change their opinion. They heavily weight their decision on previous experiences, both positive and negative, considering the fact that they have had great experiences, but also have survived the negative experiences. This allows them to make a rounded and, in their mind, well-justified decision. 
Survivalists are aware of security at events, however they do not feel the need to know about them in advance, as this would not sway their decision.

'I'd say that I don't consider security in advance' (Amy, FG1).

This ultimately means it does not impact their attendance decision. Similarly, they do not feel the need to consider alternative events, because generally their attitude is that they will attend an event no matter what, there would have to be a real disaster occur for them to feel they should not go simply because of perceived risk.

\subsection{Optimiser}

Optimisers are well-balanced indiviudals who try to justify any decision made by balancing out risk with possible satisfaction from attending an event. They will weigh up the risks that they perceive, and are moderately knowledgeable about them. They do not overly worry about risks:

\section{'I agree, [risks are] more prominent recently. If we go to a public space I am always very aware of where the girls are', 'it doesn't tend to stop us going anywhere, but I consider it before we leave'. (Chloe, FG1)}

They will seek out alternatives, just to ensure they are making the best decision for themselves; the one with the least risk, yet the most fun. Risk can impact their final decision, but only in the sense that it is likely to sway their opinion over which event option to choose, rather than dissuade them from attending an event totally. They will consider their previous experiences, thinking about the good and bad times they had, again allowing them to make the best decision possible.

Optimisers will briefly consider security measures that are in place, with Kerry (FG2) explaining that something as simple as a police presence made her feel more secure, demonstrating that she considered security, but didn't appear to worry particularly about it. They would partly like to know about security in place, but equally feel that it could be risky if, for example, terrorists also know about the security.

I think it almost telling people that the security measures are going to be this and that at the event it makes you think that if someone is going to try and get something in that they should not then even know they are going to be searched here and there so they'll know to find another way. So it's not necessarily beneficial' (Chloe, FG1).

Overall risk and security could impact their decision, but it depends on the severity of what they perceive, and will come down to details of the event specifically.

All participants agreed that the media influenced their decisions somehow, even if this pushed them to ignore the risks due to the fear it created in them. There was unanimous agreement that the way in which media portrays negative events, such as terrorism attacks, increases the immediate concern for attending an event. However, this only lasted a short period of time, and a few weeks after people continued with their lives and only those who were classed under the Overthinker, Investigator and Optimiser continued to consider these events that had occurred. In the long term, only Overthinkers thought about this, in relation to their own event attendance decision.

\section{Conclusions and Recommendations}

The aim of this work was to create a taxonomy of event participants based on risk and security perceptions. Six taxonomy categories were created based on the unique combination of attitudes and reactions: Overthinker, Investigator, Naïve, Ignorer, 
Survivalist, Optimiser. A framework containing 12 dimensions was developed to illustrate similarities and differences with regards to attitudes and reactions to risk and security. The taxonomy follows the guidelines proposed by Doty and Glick (1994) for developing typologies: 1) it defines a set of distinct types (over-thinker, investigator, naive, ignorer, survivalist, optimiser); 2) it describes each type using a consistent set of twelve dimensions, leading to rich descriptions of each type, and 3) the typology accommodates the assumption that each dimension's contribution to each type is differentially important. For example, advanced knowledge of security measures is less relevant to the ignorer when compared to the over-thinker.

The results of this research provide empirical evidence of the diverse risk and security perceptions at public events. These types reflect some of the theoretical approaches to decision-making in the context of risk elaborated upon in the literature review. Over-thinkers and Investigators appear to reflect the principles laid out in knowledge theory where people are concerned about something because they know they should be, reflected in considering the various elements of the event in relation to risk and security (Krimsky and Golding, 1992; Fischer et al., 2011). However, Investigators appear to be less extreme than Overthinkers and are keen to explore alternative options because by exploring other, potentially safer options they feel reassured that they are making the right decisions. Therefore, Investigators' decisions appear to be the result of logical and well thought out choices, which reflects the principles of rational choice theory (Jaeger et al., 2001). Optimisers share many characteristics with Investigators; however, while the latter worry about risks and therefore actively consider security measures, the former weights-up risks against the experience and therefore only briefly consider security measures. Unlike Investigators, the Optimiser tries to justify any decision made by balancing out risk with possible satisfaction from attending an event. This mindset is strongly linked with the psychometric paradigm (Jungermann et al., 1998), supporting the argument that many people attempt to balance out their risk-taking by opting for an alternative that ensures a satisfactory level of benefit.

The Naive and Ignorers show similar characteristics, in that risk and security do not impact on their decision to attend events. However, the Naive are not aware of the risks (and hence, naturally, risk and security are not an issue for them), while lgnorers are aware of risks but choose to ignore them. By not availing themselves of knowledge of what is going on in the world, the Naïve will not worry, simply due to not knowing what there is to worry about. This links to personality theory (Wildavsky and Dake, 1990), which postulates that those who have a laid back/ignorant personality generally do not concern themselves with risks which might occur. Ignorers are also strongly influenced by personality and ignore any warning signs; however, they also reflect the principles of maximisation theory (Slovic, 2000) given that their focus is on how much of a good time they can have at an event. Risk takers are categorised under the Ignorer type. Generally, they are daredevils, people who think life is for living and think that not doing something because of what might occur is foolish (Stewart et al., 2001). Survivalist predominantly encompasses individuals who have lived through worse life events, thus diluting the severity of risks that might occur. They rely heavily on past experience to justify taking risks. This links to cultural theory and the idea that lifestyle and events which they have lived through impact how they think (Douglas, 1978).

\subsection{Managerial implications}

The taxonomy provides a basis for event managers to adapt to the variety of risk and security perceptions of attendees at their events. The results demonstrate that risk and security perceptions may or may not influence event attendance. The findings of the research equip managers with knowledge about how the interplay between risk and security perceptions shapes major attendance groups. The intuitive categories and their profiles could encourage practitioners to research their audience in relation to the taxonomy. By 
identifying what the prevailing attendee categories for a specific event are, managers will be in a better position to more efficiently tackle and communicate risk and security matters.

From a communication perspective, event organisers should consider whether they need to communicate their risk management strategy, and if so how they can best achieve this. For Overthinkers, event managers will need to demonstrate control as they consider everything and feel re-assured by knowing that risk and security is well-managed. To satisfy Investigators and Optimisers, managers should publicise key security information to satisfy these individuals. Trying to put strategies in place to control perceived risk is not required for the Naives, Survivalists or Ignorers, because they do not concern themselves with risk management at events, and therefore this is unlikely to impact their decision to attend them.

If, as it is reasonable to expect, the event is found to attract a diverse set of types, a tailored communication strategy would be the most effective. Understanding what information they search for and from where would facilitate the development of such strategy. However, this may not always be feasible and in such cases it seems best to share some information about security in place as this will reassure some people, but equally keep some measures private, so as to not worry people who think those intent on causing harm might try and get around the measures in place.

\subsection{Limitations and future research}

This research is not without its limitations. This research used focus groups, a data collection technique which is subject to moderator bias and participant conformity (Fox et al, 2014). While this did not appear to be a significant issue as people often disagreed, future research could be complemented by individual, in-depth interviews. Another limitation related to data collection is that participants were mothers living in a specific region of the UK, some of whom were selected through snowball sampling, limiting the generalisability of the findings (Jones et al, 2012). Nonetheless, the focus groups included participants from a range of backgrounds, including job, family structure, number of children and amount and types of events attended. While this ensured a sufficiently wide spectrum of personalities and experiences they have lived through, future research should extend to other types of attendees selected through more representative sampling techniques.

Each category in the taxonomy is unique and has a clear set of attributes; however, fluid categories could be considered. This involves investigating if some individuals are likely to fluctuate between different categories, and the conditions that trigger those shifts, such as type of event attended and number and age of children. For example, some participants mentioned they were more concerned about the risks when attending indoor events than outdoor events. Some participants also commented on how their attitude towards risk and security had adapted as they had more children and as their children grew older. In addition, given the growing number of serious incidents affecting events which are widely reported in traditional and social media, future research could also examine the extent to which such coverage is leading to shifts in the predominant categories which event participants belong to.

This research was exploratory in nature and follow-up work could therefore be done to further validate the findings of the taxonomy (Fox et al, 2014). An obvious future step involves validating the taxonomy using quantitative methods. The typology and its dimensions presented in Figure 2 provide a good basis for scale development which underpins this type of research. Quantitative research could also expand the profile of each category by examining the relationship between category membership and variables such as country/culture, number and age of children, personal experience with security incidents, risk-taking propensity and event attendance experience. Finally, this research focused mainly on 'process' (how risk and security perceptions shape the categories) and future 
research could attempt to incorporate the 'content' component, in the form of the value attached by relevant taxonomy categories to particular types of risks and security measures.

\section{References}

BBC, 2017. Manchester attack: 22 dead and 59 hurt in suicide bombing, Available at: http://www.bbc.co.uk/news/uk-england-manchester-40010124 (accessed April 23 2018)

Bennett, C.J. and Haggerty, K., 2012. Security Games: Surveillance and Control and Mega-Events. London: Routledge.

Bruwer, J. and Rawbone-Viljoen, C., 2013. BYOB as a risk-reduction strategy (RRS) for wine consumers in the Australian on-premise foodservice sector: Exploratory insights. International Journal of Hospitality Management, 32, pp.21-30.

Chan, E.S. and Lam, D., 2013. Hotel safety and security systems: Bridging the gap between managers and guests. International Journal of Hospitality Management, 32, pp.202-216.

Chicago Tribune, 2018. Incidents of sexual harassment, assault high at music festivals, new survey reveals, Available at: http://www.chicagotribune.com/lifestyles/ct-life-music-festivals-sexualassaults-0328-story.html (accessed April 23 2018)

Collier, D., LaPorte, J. and Seawright, J., 2012. Putting typologies to work: Concept formation, measurement, and analytic rigor. Political Research Quarterly, 65(1), pp.217-232.

DeLamater, J., and Ward, A., 2013. Handbook of Social Psychology. $2^{\text {nd }}$ Edition. London: Springer.

Dolnicar, S., 2005. Understanding barriers to leisure travel: Tourist fears as a marketing basis. Journal of Vacation Marketing, 11(3), 197-208.

Doty, D. H., and Glick, W. H., 1994. Typologies as a unique form of theory building: Toward improved understanding and modeling. Academy of management review, 19(2), 230-251.

Douglas, M., 1978. Cultural Bias. London: Royal Anthropological Institute.

Elman, C., 2005. Explanatory typologies in qualitative studies of international politics. International organization, 59(2), pp.293-326.

Floyd, M. F. and Pennington-Gray, L., 2004. Profiling risk perceptions of tourists. Annals of Tourism Research, 31(4), 1051-1054.

Fox, D., Gouthro, M.B., Morakabati, Y. and Brackstone, J., 2014. Doing events research: From theory to practice. Routledge.

Freeston, M.H., Rheaume, J., Letarte, H., Dugas, M.J. and Ladouceur, R., 1994. Why do people worry? Personality and Individual Differences, 17 (6), 791-802.

Fuchs, G. and Reichel, A., 2011. An exploratory inquiry into destination risk perceptions and risk reduction strategies of first time vs. repeat visitors to a highly volatile destination. Tourism Management, 32(2), pp.266-276.

Getz, D. and Page, S., 2016. Event studies: Theory, research and policy for planned events. Routledge.

Globo, 2017. Camarote desaba durante show de Ivete Sangalo e 26 pessoas foram encaminhadas a hospitais [Platform collapses during Ivete Sangalo's show and 26 receive hospital treatment] Available at: https://g1.globo.com/se/sergipe/noticia/camarote-desaba-durante-show-de-ivetesangalo-em-aracaju.ghtml (accessed April 23 2018)

Guardian, 2017. More than 22,000 evacuated as fire engulfs stage at music festival in Spain, Available at: https://www.theguardian.com/world/2017/jul/30/more-22000-evacuated-as-fire-hitsspain-music-festival (accessed April 23 2018) 
Hajibaba, H., Gretzel, U., Leisch, F. and Dolnicar, S., 2015. Crisis-resistant tourists. Annals of Tourism Research, 53, pp.46-60.

Holloway, I., and Wheeler, S., 2010. Qualitative research in nursing and healthcare, 3rd ed., Oxford, Wiley-Blackwell.

Jackson, S. and Groves, C., 2015. Taxonomy of Australian Mammals. Clayton South: CSIRO Publishing.

Jaeger, C.C., Renn, O., Rosa, R.A. and Webler, T., 2001. Risk, Uncertainty and Rational Action. Abingdon: Earthscan Publications Ltd.

James, W., 1913. The Principles of Psychology. American Science Series, 2, 708-730.

Jayawardhana, A., 2016. Ensuring Security Against the Threats of Terrorist Acts in Mega Sport Events. International Journal of Sport Management, Recreation \& Tourism, 25, 1-9.

Jones, I., Holloway, I. and Brown, L., 2012. Qualitative Research in Sport and Physical Activity, Sage, London.

Jungermann, H., Pfister, H.R. and Fischer, K., 1998. Die Pyschologie der Entscheidung. Eine Einführing. Heidelberg and Berlin: Spektrum Verlag.

Kaplan, R.S. and Mikes, A., 2012. Managing Risks: A New Framework. Boston: Harvard Business Review. Available from: https://hbr.org/2012/06/managing-risks-a-new-framework [Accessed on 17th November 2016].

Kim, S.S., Choi, S., Agrusa, J., Wang, K.C. and Kim, Y., 2010. The role of family decision makers in festival tourism. International Journal of Hospitality Management, 29(2), pp.308-318.

Kovacich, G.L. and Halibozek, E.P., 2006. Security Metrics Management: How to Measure the Costs and Benefits of Security. Oxford: Butterworth Heinemann.

Krimsky, S. and Golding, D., 1992. Social Theories of Risk. Connecticut: Praeger.

Lavino, J.G. and Neumann, R.B., 2010. Psychology of Risk Perception. New York: Nova Science Publishers.

Milman, A., Jones, F. and Bach, S., 1999. The impact of security devices on tourists' perceived safety: The central Florida example. Journal of Hospitality \& Tourism Research, 23(4), pp.371-386.

Mitchell, V.W. and Boustani, P., 2015. The effects of demographic variables on measuring perceived risk. In Proceedings of the 1993 Academy of Marketing Science (AMS) Annual Conference (pp. 663669). Springer, Cham.

Mitchell, V.W., 1999. Consumer perceived risk: conceptualisations and models. European Journal of marketing, 33(1/2), pp.163-195.

New York Times. 2013. Blasts at Boston Marathon Kill 3 and Injure 100, Available at: https://www.nytimes.com/2013/04/16/us/explosions-reported-at-site-of-boston-marathon.html (accessed April 23 2018)

Nissen, A. and Heir, T., 2016. Perceived safety at work in the wake of terror: the importance of security measures and emergency preparedness. Disaster medicine and public health preparedness, 10(6), pp.805-811.

Ritchie, B.W., Chien, P.M. and Sharifpour, M., 2017. Segmentation by Travel Related Risks: An Integrated Approach. Journal of Travel \& Tourism Marketing, 34 (2), 274-289.

Rittichainuwat, B.N. and Chakraborty, G., 2012. Perceptions of importance and what safety is enough. Journal of Business Research, 65(1), pp.42-50.

Rittichainuwat, B.N., 2013. Tourists' perceived risks toward overt safety measures. Journal of Hospitality \& Tourism Research, 37(2), pp.199-216.

Roehl, W. S. and Fesenmaier, D. R., 1992. Risk perceptions and pleasure travel: An exploratory analysis. Journal of Travel Research, 30(4), 17-26. 
Saadat, S., Naseripour, M., Karbakhsh, M. and Rahimi-Movaghar, V., 2010. Perceived risk and risktaking behavior during the festival firework. American journal of health behavior, 34(5), pp.525-531.

Schäfer, A. and Klammer, J., 2016. Service Dominant Logic in Practice: Applying Online Customer Communities and Personas for the Creation of Service Innovations. Management (18544223), 11(3).

Schroeder, A., Pennington-Gray, L., Kaplanidou, K. and Zhan, F., 2013. Destination risk perceptions among US residents for London as the host city of the 2012 Summer Olympic Games. Tourism Management, 38, pp.107-119.

Seabra, C., Dolnicar, S., Abrantes, J.L. and Kastenholz, E., 2013. Heterogeneity in risk and safety perceptions of international tourists. Tourism Management, 36, 502- 510.

Sjoberg, L., 1998. Worry and Risk Perception. Risk Analysis, 18 (1), 85-93.

Slovic, P., 2000. The Perception of Risk. London: Earthscan.

Stewart, J., Wayne, H. and Roth, P.L., 2001. Risk propensity differences between entrepreneurs and managers: A meta-analytic review. Journal of Applied Psychology [online], 86(1), 145-153.

Taylor, T. and Toohey, K., 2005. Impacts of terrorism-related safety and security measures at a major sport event. Event Management, 9(4), pp.199-209.

The Daily Meal, 2017. Oyster Festival Sickens 145 Attendees, Venue Hosts Another Two Weeks Later, Available at: https://www.thedailymeal.com/healthy-eating/oyster-festival-foodpoisoning/111317 retrieved (accessed April 23 2018)

The Outline, 2018. Here's an interactive map of all the crimes committed during Coachella week. Available at: https://theoutline.com/post/4229/coachella-crime-map (accessed April 23 2018)

Toohey, K. and Taylor, T., 2008. Mega events, fear, and risk: Terrorism at the Olympic Games. Journal of Sport Management, 22(4), pp.451-469.

Walters, G., Shipway, R., Miles, L. and Aldrigui, M., 2017. Fandom and risk perceptions of Olympic tourists. Annals of Tourism Research, 66, pp.210-212.

Wildavsky, A. and Dake, K., 1990. Theories of Risk Perception: Who Fears What and Why? Daedalus, 119 (4), 41-60.

Wynn-Moylan, P., 2017. Risk and Hazard Management for Festivals and Events. Routledge. 